\title{
Operation Planning of Hydro Stations Using Genetic Algorithms Considering their Impact on the Electricity Market Prices
}

\author{
Carlos A. Guerreiro and João Tomé Saraiva
t. de Engenharia Eletrotécnica e Computadores da FEUP \\ Carlos A. Guerreiro and João Tomé Saraiva
Dept. de Engenharia Eletrotécnica e Computadores da FEUP \\ INESC Porto, Porto, Portugal \\ ee07401@fe.up.pt and jsaraiva@fe.up.pt
}

\begin{abstract}
With the advent of restructuring, generation companies have to plan the operation of their stations in order to maximize their profits. This is very relevant for companies having a large share of hydro stations, and even more if these stations have pumping capacity. This paper describes a model to plan the operation of a set of hydro stations eventually installed in cascade and admitting that some of them are pumping stations. Once a first set of operation orders is obtained using a Genetic Algorithm, their generation/load values are included in the expected market selling/buying curves and the hourly prices are updated. These prices are then used to refine the operation orders originating an iterative process so that hydro stations are price makers. The paper includes results for a hydro system in order to illustrate the application of the developed approach.
\end{abstract}

Index Terms-hydro stations, electricity markets, price makers, optimization, Genetic Algorithms.

\section{INTRODUCTION}

In several European countries hydro generation plays an important role in the supply of electricity. In the past, under the vertically integrated paradigm that governed the sector, the operation of hydro stations was directed by long term planning considerations, namely regarding reservoirs. In recent years, the advent of electricity markets and the rapid increase of other renewable sources as wind power put a new emphasis on the identification of the most adequate operation strategies for hydro stations on the short term (namely for the next day or week), both run-of-river and reservoirs.

In recent publications we have developed short term operation planning models for hydro stations namely installed in cascade taking into account electricity markets prices that is admitting that hydro stations behave as price takers $[1,2]$ using an under relaxation approach and Genetic Algorithms. However, in countries as in Portugal the share of hydro generation is typically large (in average hydro years it can reach $25 \%$ of the total electricity generation) so that taking hydro stations as just price takers becomes far from reality. Accordingly, this paper gives a further step in this problem considering the impact of their operation in the electricity market prices. This means moving from considering hydro

\author{
J. C. Sousa and V. T. Mendes \\ EDP Gestão da Produção SA, Porto \\ Portugal \\ jose.sousa@edp.pt and virgilio.mendes@edp.pt
}

stations as just price takers and we are now admitting they influence market prices and so they behave as price makers.

The mathematical model used to obtain the most adequate operation strategy of a set of hydro stations considers the non linear relation between the power, the water flow and the head, as well as the possibility of pumping. The results provided by this model correspond to the operation strategy that maximizes the profit of the generation agent along the 24 hours of a trading day or along a week. In order to consider the impact on electricity prices, this model is then included in an iterative procedure that starts with a set of initial electricity prices for each hour of the planning horizon together with the demand curve and the estimated selling curve for the remaining generation agents, solves the mentioned profit maximization problem using Genetic Algorithms [2], updates the hourly market selling and buying aggregated curves and makes the intersection of these curves to update the hourly prices. These prices are then input again in the profit maximization problem to progressively refine the operation decisions of the hydro stations.

\section{BRIEF LITERATURE REVIEW ON HYDRO SCHEDULING}

The hydro scheduling problem is traditionally a complex one given its non linear nature and the temporal and spatial interdependencies between stations. Admitting we are panning the operation of station $\mathrm{i}$ in period $\mathrm{k}$ and assuming an ideal hydro circuit, the generated power is given by (1) in which the gravity acceleration is $9,8 \mathrm{~ms}^{-2}$, the density of the water is $1000 \mathrm{~kg} / \mathrm{m}^{3}, \mathrm{q}_{\mathrm{ik}}$ is the water flow in $\mathrm{m}^{3} \mathrm{~s}^{-1}, \mathrm{~h}_{\mathrm{ik}}$ is the water head in $\mathrm{m}$ and $\mu_{\mathrm{T}}$ is the generation efficiency factor.

$$
\mathrm{P}_{\text {Tik }}=9,8.1000 \cdot \mathrm{q}_{\mathrm{ik}} \cdot \mathrm{h}_{\mathrm{ik}} \cdot \mu_{\mathrm{T}}
$$

The water head displays a non linear dependency on the water flow creating losses in the water circuit. In order to consider this effect, expression (1) is substituted by (2) in which $\beta$ represents the head loss coefficient. For each particular value of $h_{i k}$ one obtains a non-linear expression relating $\mathrm{q}_{\mathrm{ik}}$ and $\mathrm{P}_{\mathrm{Tik}}$, that is, expression (2) corresponds to a family of curves as illustrated in Figure 1. The head loss 
coefficient $\beta$ is calculated using (3) where $\Delta$ hn is the nominal head loss and qn is the nominal discharge flow. After obtaining $\beta$, the generated power $\mathrm{P}_{\text {Tik }}$ still displays a non linear dependence on the water flow, $\mathrm{q}_{\mathrm{ik}}$, due to the term ß. $\mathrm{q}_{\mathrm{ik}}^{2}$ in (2). This non linear relation is illustrated in Figure 1.

$$
\begin{gathered}
\mathrm{P}_{\text {Tik }}=9,8.1000 \cdot \mathrm{q}_{\mathrm{ik}} \cdot\left(\mathrm{h}_{\mathrm{ik}}-\beta \cdot \mathrm{q}_{\mathrm{ik}}^{2}\right) \mu_{\mathrm{T}} \\
\beta=\frac{\Delta \mathrm{hn}}{\mathrm{qn}^{2}}
\end{gathered}
$$

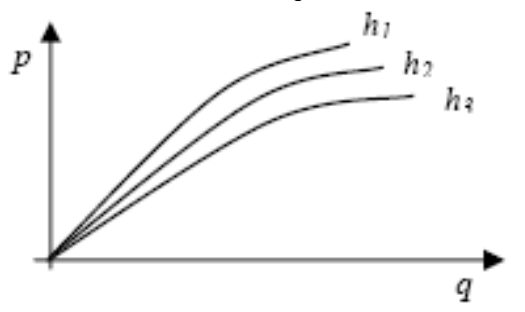

Figure. 1. Family of curves for the generated power of a hydro station.

The non-linear dependency between the power, the head and the flow is one the reasons for the complexity of the hydro scheduling problem that justified the adoption of several approximations.. One possible approximation corresponds to neglect the head loss term in (2) so that for a particular value of $h_{i k}$ a linear approximation is used. This approximation would be located above the real curve leading to poorer results for larger flows. This is not desirable because the experience shows that, when generating, hydro stations are operating for large values of the flows to increase the revenues. A second possibility corresponds not only to neglect the head loss term but also to consider a fixed value for the head, $h_{i k}$, itself. This is useful for stations with very large reservoirs so that the head is very little changed after some hours of operation. However, it proves to be unrealistic for run of river stations or small reservoirs in which the capacity and the head can easily get strongly reduced after operating for some periods. This means that the approximation to be used depends on the characteristics of each hydro station.

To maximize the operation profits, generation companies have been enlarging the stations having pumping capacity, either when building new ones or by substituting equipments in existing stations whenever that is possible. In case of pumping, the power consumed by station $\mathrm{i}$ in period $\mathrm{k}$ is given by (4) where $\mu_{P}$ is the pumping efficiency factor.

$$
\mathrm{P}_{\mathrm{Pik}}=9,8.1000 \cdot \mathrm{q}_{\mathrm{ik}} \cdot\left(\mathrm{h}_{\mathrm{ik}}+\beta \cdot \mathrm{q}_{\mathrm{ik}}^{2}\right) / \mu_{\mathrm{P}}
$$

The non-linear nature of the hydro scheduling problem justified the use of non-linear optimization techniques as in [3, 4]. Dynamic programming has also been reported $[5,6,7]$ but the curse of dimensionality of dynamic programming turned difficult to model real systems. In an attempt to simplify the problem, several approximations were tested eventually leading to linear formulations as in $[3,8]$ usually using a linear relation between the power and the flow. Other models include binary variables as [9] to represent the state of each station leading to mixed integer linear or non-linear formulations. More recently, metaheuristic techniques started to be applied to this problem including Neural Networks [10], Simulated Annealing [11], Tabu Search [12], Genetic Algorithms [2, 13] and particle swarm approaches [14]. Finally, several publications $[1,15]$ use an iterative process in which the head is updated using the value of $q_{i k}$ got in the previous iteration and the $\beta$ coefficient is given by (3).

\section{Mathematical Formulation Of THE Problem ASSUMING HYDRO STATIONS AS PRICE TAKERS}

In this section we detail the mathematical formulation of the Short-Term Hydro Scheduling, STHS, problem using a set of prices that are unchanged. The STHS model maximizes the profit of a set of hydro plants over a horizon typically of one day or one week with an hourly discretization. We also assumed that there is an upper level model that is used to simulate a medium/long term horizon and that provides the initial and final volumes of each station to be used in STHS.

$$
\begin{aligned}
& \max \sum_{\mathrm{i}=1 \mathrm{k}=1}^{\mathrm{I}} \sum_{[}^{\mathrm{K}}\left[\left(\pi_{\mathrm{k}} \cdot \mathrm{P}_{\mathrm{Tik}}\right)-\left(\pi_{\mathrm{k}} \cdot \mathrm{P}_{\mathrm{Pik}}\right)-\left(\mathrm{ps} \cdot \mathrm{s}_{\mathrm{ik}}\right)\right] \\
& \mathrm{v}_{\mathrm{ik}}=\mathrm{v}_{\mathrm{i}(\mathrm{k}-\mathrm{l})}+\mathrm{a}_{\mathrm{ik}}-\mathrm{q}_{\mathrm{Tik}}-\mathrm{s}_{\mathrm{ik}}+\mathrm{q}_{\mathrm{Pik}}+ \\
& \text { subj. } \\
& v_{i k}=v_{(k-1)}+a_{i k}-q_{i k}-s_{i k}+q_{P i k} \\
& +\sum_{\mathrm{m} \in \mathrm{Mi}}\left(\mathrm{q}_{\mathrm{Tm}\left(\mathrm{k}-\phi_{\mathrm{m}}\right)}+\mathrm{s}_{\mathrm{m}\left(\mathrm{k}-\lambda_{\mathrm{m}}\right)}-\mathrm{q}_{\mathrm{Pm}\left(\mathrm{k}-\omega_{\mathrm{m}}\right)}\right) \\
& \operatorname{vol}_{\mathrm{i}}^{1 \mathrm{~min}} \leq \mathrm{q}_{\mathrm{Tik}}+\mathrm{s}_{\mathrm{ik}}-\mathrm{q}_{\mathrm{Pik}} \leq \mathrm{vol}_{\mathrm{i}}^{1 \mathrm{max}} \\
& \mathrm{v}_{\mathrm{i}}^{\min } \leq \mathrm{v}_{\mathrm{ik}} \leq \mathrm{v}_{\mathrm{i}}^{\max } \\
& \mathrm{qT}_{\mathrm{i}}^{\min } \leq \mathrm{qT}_{\mathrm{ik}} \leq \mathrm{qT}_{\mathrm{i}}^{\max } \\
& \mathrm{qP}_{\mathrm{i}}^{\min } \leq \mathrm{qP}_{\mathrm{ik}} \leq \mathrm{qP}_{\mathrm{i}}^{\max } \\
& 0 \leq \mathrm{s}_{\mathrm{ik}} \leq \infty \\
& \mathrm{v}_{\mathrm{iK}}=\mathrm{vol}_{\mathrm{iK}} \\
& \mathrm{i}=1, \ldots, \mathrm{I} ; \mathrm{k}=1, \ldots, \mathrm{K} ; \mathrm{m}=1, \ldots, \mathrm{L}
\end{aligned}
$$

In this formulation:

- I, i - number of reservoirs and index for a reservoir;

- K , $\mathrm{k}$ - number of periods and index for a particular hour;

- Mi - set of upstream reservoirs directly connected with $\mathrm{i}$;

- $\mathrm{m}$ - index for a reservoir in set $\mathrm{Mi}$;

- $\pi_{\mathrm{k}}$ - electricity market price in hour $\mathrm{k}$;

- $\mathrm{P}_{\mathrm{T}_{\mathrm{ik}}}, \mathrm{P}_{\mathrm{P}_{\mathrm{ik}}}$ - generated/pumping power in station $\mathrm{i}$, hour $\mathrm{k}$;

- ps - penalty factor for spills;

- $v_{i k}, s_{i k}, a_{i k}-$ volume, spill and inflow of reservoir $i$, in hour k;

- $\mathrm{q}_{\mathrm{Pik}}, \mathrm{q}_{\mathrm{Tik}}-$ pumping/discharge volume of reservoir $\mathrm{i}$, in hour k;

- $\phi_{\mathrm{m}}, \lambda_{\mathrm{m}}, \omega_{\mathrm{m}}-$ delays of turbine discharge, spill and pumping volumes;

- $\operatorname{vol}_{i}^{1 \mathrm{~min}}, \mathrm{vol}_{\mathrm{i}}^{\mathrm{lmax}}$ - min. and max. volumes of reservoir i;

- $v_{i}^{\min }, v_{i}^{\max }$ - level volume limits of reservoir $\mathrm{i}$;

- $\mathrm{qT}_{\mathrm{i}}^{\min }, \mathrm{qT}_{\mathrm{i}}^{\max }$ - turbine discharge limits for station $\mathrm{i}$;

- $\mathrm{qP}_{\mathrm{i}}^{\min }, \mathrm{qP}_{\mathrm{i}}^{\max }$ - pumping volume limits for station $\mathrm{i}$;

- ${ }^{v o l} l_{\mathrm{K}}$ - volume of reservoir $\mathrm{i}$ in the last period, $\mathrm{K}$. 
The objective function (5) maximizes the profit obtained by selling the generated power at each period $\mathrm{k}$ of station $\mathrm{i}$, $\mathrm{P}_{\mathrm{T}_{\mathrm{ik}}}$, at the market price $\pi_{\mathrm{k}}$ subtracted by the cost of buying power if the station is pumping. If spilling occurs then the third term in (5) penalizes these situations. The equality constraints (6), one per station $i$ and period $k$, relates $v_{i k}$ with the volume of reservoir $i$ in period $k-1$, with the inflow, with the outflow, with the spill and with the water balance in the upstream reservoirs directly connected with i. Constraints (7) set min and max limits for the output volume of reservoir $i$, modeling for instance minimum flow requirements related with agriculture uses or ecological reasons. Constraints (8) bound the hourly volumes of reservoir $i$ and (9) and (10) limit the generation and pumping flows of station $\mathrm{i}$ in period $\mathrm{k}$. Finally, constraints (11) indicate that the water spill is nonnegative and (12) sets the volume of reservoir $\mathrm{i}$ at the end of the planning period, that is, at the end of hour $\mathrm{K}$.

\section{APPliCATION OF GA's TO THE SHORT TERM HydRO SCHEDULLING CONSIDERING THE IMPACT ON PRICES}

The previous optimization problem requires that a set of hourly prices is provided. To turn the scheduling results more realistic, and specially for generation companies or countries having a large share of hydro generation, it is important to consider the impact of the hydro scheduling in the market prices, that is considering them as price makers. To do this, the more global procedure illustrated in Figure 2 was used.

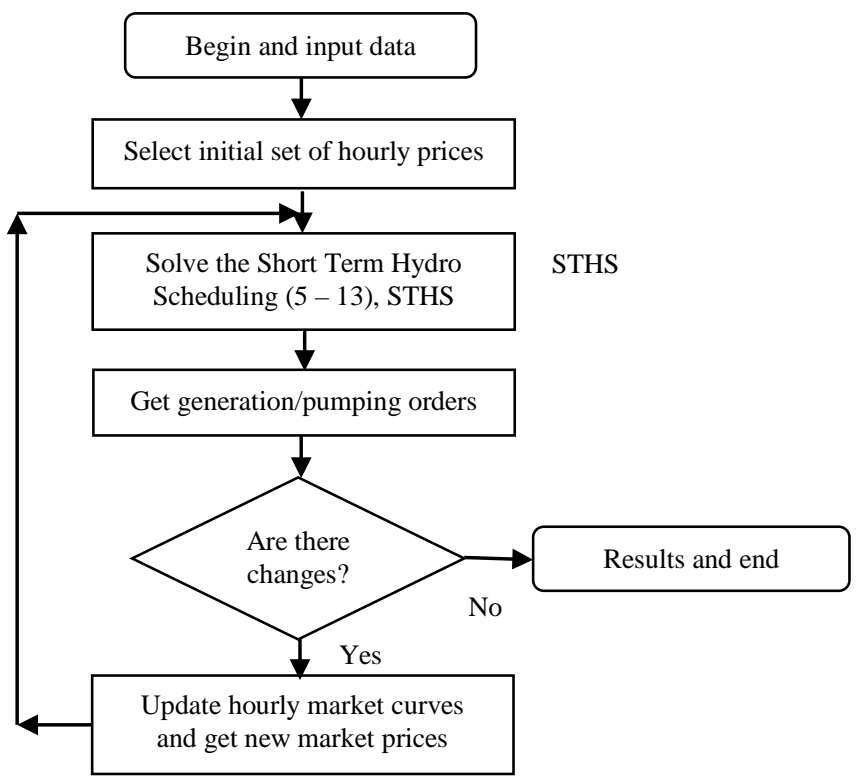

Figure 2. Algorithm to consider the hydro stations as price makers.

According to this flowchart, the STHS problem is run a first time using an initial set of prices. Afterwards, we get the generation and pumping orders that are used to change the aggregated market demand and selling curves. Based on historical values, we admit knowing expected demand and generation curves for the remaining market agents. For each hour, the selling curve is moved to the right using the sum of the generation orders of all stations. The demand curve is also moved to the right side using the demand of the stations that are pumping. After doing this for every hour, each pair of demand/generation curves is crossed and a new market price is obtained for that hour. The updated market hourly prices are input to the STHS module again to adjust the operation orders. This defines an iterative procedure that continues until from one iteration to the next one there is no change of the operation mode of any station for any hour of the horizon.

We will now detail the Genetic Algorithm used to solve the problem on block STHS of Figure 2 which corresponds to the problem described in Section III. Genetic Algorithms are well suited to solve problems including integer or binary variables. Regarding the STHS problem, the decision variables are the discharging and pumping flows in each hour which are continuous variables. However, the recent practice of generation companies suggests that when generating the flow is at the maximum and when pumping the flow is also at the maximum possible. These extreme operation strategies are induced by the attempt to maximize the profits. Accordingly, in this application we admitted that flows were at the maximum possible values as it was used in [2]. Therefore, the flows will no longer correspond to decision variables because they are substituted by the status of the each station so that the following coding was used: $00-$ not active; 01 - operating as a pump; 10 - operating as a generator; 11 - not active.

Accordingly, to model the state of each station in each hour a string of 2 bits is required. Having a hydro system with I stations and an horizon with $\mathrm{K}$ hourly periods, the chromosomes have 2.K.I bits. After setting the number of individuals, the main steps of the GA are as follows:

i) Initialization - the initial population is randomly sampled;

ii) Evaluation - each chromosome codes a possible solution to the problem $(5-13)$. Each solution is evaluated identifying the state of each station i. If generating then (2) is used to obtain the generated power and if pumping then (4) is used. These expressions use the flow $q_{i k}$ and the head $h_{i k}$. The flow is set at $\mathrm{qT}_{\mathrm{i}}^{\max }$ for the generation 10 state and at ${ }_{\mathrm{PP}_{\mathrm{i}}} \max$ for the pumping 01 state. These values together with the hourly market prices are then used to obtain the objective function (5). Regarding the constraints, the fitness function includes penalty terms for violated ones;

iii) Convergence - convergence is obtained if the conjunction of the next conditions holds: the average value of the fitness function did not change more than a specified percentage when compared with the values in previous iterations, if its standard deviation is smaller than a pre-set limit and if the largest value of the fitness function (the one of the best individual) didn't change more than a specified percentage for a number of iterations;

iv) Genetic operators - if the iterative process did not converge yet, then the genetic operators are used to create a new population. Selection is done submitting pairs of individuals to a stochastic tournament to select the most adapted one. Then, selected pairs of individuals are submitted to crossover and finally mutation is used to change one bit of some randomly selected individuals. At the end, the new population is returned back to step ii). 


\section{RESULTS USING A CASCADE OF HYDRO STATIONS}

\section{A. Data of the test hydro system}

The hydro test system includes four stations all having the possibility of pumping. Their main characteristics are detailed in Table I. Table II has the hourly inflows as well as the initial electricity market prices, admitting that the operation planning horizon of the this hydro system is 24 hours.

TABLE I. CHARACTERISTICS OF THE HYDRO STATIONS.

\begin{tabular}{|l|c|c|c|c|}
\cline { 2 - 5 } \multicolumn{1}{c|}{} & Hydro_1 & Hydro_2 & Hydro_3 & Hydro_4 \\
\hline Initial vol. $\left(\mathrm{hm}^{3}\right)$ & 900 & 20 & 30 & 9 \\
\hline Final vol. $\left(\mathrm{hm}^{3}\right)$ & 900 & 20 & 30 & 9 \\
\hline Min. vol. $\left(\mathrm{hm}^{3}\right)$ & 800 & 10 & 10 & 8 \\
\hline Max. vol. $\left(\mathrm{hm}^{3}\right)$ & 1000 & 30 & 50 & 10 \\
\hline $\mathrm{qT}_{\mathrm{i}}^{\max }\left(\mathrm{m}^{3} / \mathrm{s}\right)$ & 400 & 120 & 70 & 50 \\
\hline $\mathrm{qP}_{\mathrm{i}}^{\max }\left(\mathrm{m}^{3} / \mathrm{s}\right)$ & 400 & 120 & 70 & 50 \\
\hline Nom. head $(\mathrm{m})$ & 50 & 100 & 150 & 500 \\
\hline$\mu_{\mathrm{T}}$ & 0.88 & 0.89 & 0.89 & 0.9 \\
\hline$\mu_{\mathrm{P}}$ & 0.92 & 0.93 & 0.93 & 0.93 \\
\hline Head loss, $\beta$ & $7.813 .10^{-6}$ & $173.6 .10^{-6}$ & $765.10^{-6}$ & $5000.10^{-6}$ \\
\hline
\end{tabular}

TABLE II. INITIAL MARKET PRICES AND INFLOWS.

\begin{tabular}{|c|c|c|c|c|c|}
\hline hour & $\begin{array}{c}\text { Market } \\
\text { price } \\
(€ / \mathrm{MWh})\end{array}$ & $\begin{array}{c}\text { Inflow } \\
\text { hydro_1 } \\
\left(\mathrm{m}^{3} / \mathrm{s}\right)\end{array}$ & $\begin{array}{c}\text { Inflow } \\
\text { hydro_2 } \\
\left(\mathrm{m}^{3} / \mathrm{s}\right)\end{array}$ & $\begin{array}{c}\text { Inflow } \\
\text { hydro_3 } \\
\left(\mathrm{m}^{3} / \mathrm{s}\right)\end{array}$ & $\begin{array}{c}\text { Inflow } \\
\text { hydro_4 } \\
\left(\mathrm{m}^{3} / \mathrm{s}\right)\end{array}$ \\
\hline 1 & 36.563 & 100 & 50 & 0 & 50 \\
\hline 2 & 26.635 & 100 & 50 & 0 & 50 \\
\hline 3 & 33.725 & 100 & 50 & 0 & 50 \\
\hline 4 & 34.148 & 0 & 50 & 0 & 50 \\
\hline 5 & 38.587 & 0 & 50 & 0 & 50 \\
\hline 6 & 35.238 & 0 & 50 & 0 & 50 \\
\hline 7 & 53.883 & 0 & 50 & 0 & 50 \\
\hline 8 & 65.921 & 0 & 50 & 0 & 50 \\
\hline 9 & 68.746 & 0 & 50 & 0 & 50 \\
\hline 10 & 75.866 & 0 & 50 & 0 & 50 \\
\hline 11 & 82.731 & 0 & 50 & 0 & 50 \\
\hline 12 & 89.319 & 0 & 50 & 0 & 50 \\
\hline 13 & 88.124 & 0 & 50 & 100 & 50 \\
\hline 14 & 94.636 & 0 & 50 & 100 & 50 \\
\hline 15 & 100.836 & 0 & 50 & 100 & 50 \\
\hline 16 & 109.879 & 0 & 50 & 100 & 50 \\
\hline 17 & 117.988 & 0 & 50 & 100 & 50 \\
\hline 18 & 122.907 & 0 & 50 & 0 & 50 \\
\hline 19 & 126.653 & 0 & 50 & 0 & 50 \\
\hline 20 & 112.772 & 0 & 50 & 0 & 50 \\
\hline 21 & 111.304 & 0 & 50 & 0 & 50 \\
\hline 22 & 100.137 & 0 & 50 & 0 & 50 \\
\hline 23 & 102.239 & 0 & 50 & 0 & 50 \\
\hline 24 & 98.845 & 0 & 0 & 0 & 50 \\
\hline
\end{tabular}

B. Results for Test 1

In the first test inflows were not used and the volumes in the first and final periods are the same. Given that inflows are not considered, to ensure that the initial and final volumes are equal the number of generation hours has to be equal to the number of pumping hours. The results obtained with this test confirmed these conclusions. This first test was also used to select a number of parameters to be used by the GA that is included in the iterative process described in Section IV.

\section{Results for Test 2}

In this case, we are considering inflows and so the number of generation periods can be larger than the number of pumping periods. Figures 3 and 4 show the pumping and generating periods of stations 1 and 3 and the evolution of the price. The red bars represent pumping hours and the blue ones are the generation hours. The left vertical axis has values from 0 to 1 and the mentioned bars are all at 1 indicating that the maximum generation or pumping flows were used. The right vertical axe has the electricity prices in $€ / M W h$. For station 1 the inflows are small compared with the discharges and so the generation hours exceed the number of pumping hours just by 1 . However, for station 3 the inflows are larger and so the generation hours largely exceed the pumping ones.

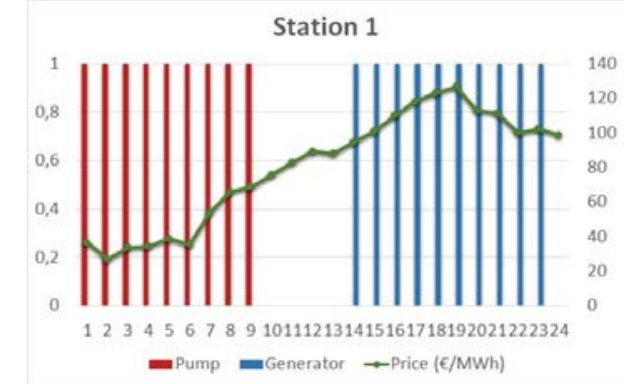

Figure 3. Generation and pumping periods for Station 1.

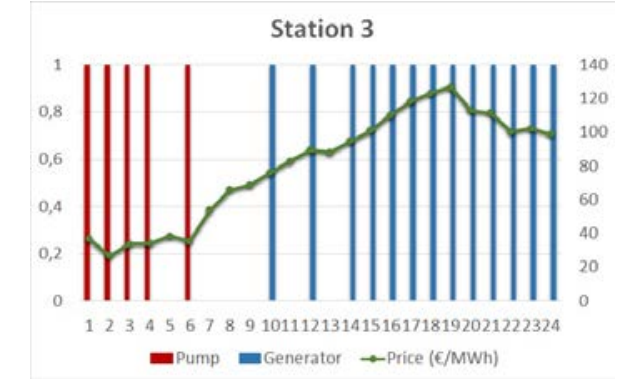

Figure 4. Generation and pumping periods for Station 3.

\section{Results for Test3}

In this test we used the head loss in (2) and (4). For station 4 , the inflows and the discharged flow are equal (see Tables I and II) so that it can operate as a generator along the day increasing the profit. After running the first iteration of the process detailed in Section IV the initial profit was $739413.18 €$. At the end of the iterative process, the profit reduces by $10606.29 €$ to $728806.89 €$. This is explained because in the pumping periods the price tends to increase, while in the generation periods the price is reduced.

\section{E. Results for Test 4}

In Test 4 we assumed that station 2 is downstream station 1 and that the lead time is 1 hour. Figure 5, 6 and 7 detail the generation and pumping periods of stations 1 to 3 and Table III lists the hourly price variations regarding the initial values in Table II. Once again, station 4 is operating as a generator all through the day, as justified for Test 3. The connection between stations 1 and 2 makes it possible for station 2 to operate along the day without pumping. It should be noticed that the discharge flow of station 1 is larger than the discharge flow of station 2 and so it is possible to use water 
both by station 2 to generate and by station 1 to pump as it happens in hours 1, 4 and 6 (see Figures 5 and 6).

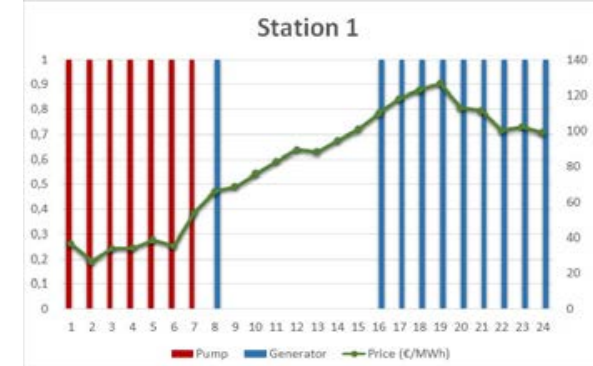

Figure 5. Generation and pumping periods for Station 1.

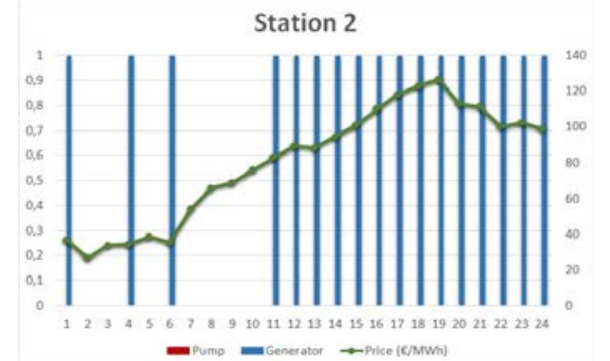

Figure 6. Generation and pumping periods for Station 2.

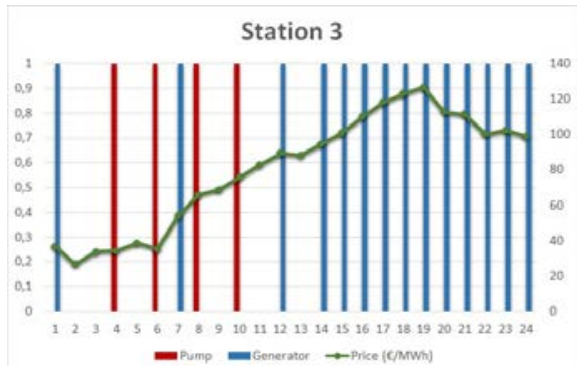

Figure 7. Generation and pumping periods for Station 3.

TABLE III. MARKET PRICE VARIATION (€/MWH).

\begin{tabular}{|c|c|c|c|c|c|}
\hline hour & $\begin{array}{c}\text { price } \\
\text { variation }\end{array}$ & hour & $\begin{array}{c}\text { price } \\
\text { variation }\end{array}$ & hour & $\begin{array}{c}\text { price } \\
\text { variation }\end{array}$ \\
\hline 1 & -0.159 & 9 & -0.356 & 17 & -1.776 \\
\hline 2 & 0.002 & 10 & -0.190 & 18 & -1.856 \\
\hline 3 & 0.002 & 11 & -0.657 & 19 & -1.912 \\
\hline 4 & 0.010 & 12 & -0.921 & 20 & -1.627 \\
\hline 5 & 0.003 & 13 & -0.697 & 21 & -1.597 \\
\hline 6 & 0.010 & 14 & -0.973 & 22 & -1.374 \\
\hline 7 & -0.106 & 15 & -1.046 & 23 & -1.421 \\
\hline 8 & -0.430 & 16 & -1.636 & 24 & -1.343 \\
\hline
\end{tabular}

Regarding the profit, its initial value is $797216.15 €$ and is reduced by $10239.88 €$ to $786976.27 €$ considering the stations as price makers. The initial and the final profits are larger than the ones obtained in Test 3 because the hydro connection between stations 1 and 2 improves the efficiency of the system reducing the number of pumping hours of station 2 and increasing its generation hours. This means that this connection reduces the pumping costs and increases the revenues obtained from selling electricity.

\section{CONCLUSIONS}

This paper describes a model to consider the impact of hydro stations in the electricity market prices while obtaining the generation and pumping periods that maximize the operation profit. Previous research works on this area admit that hydro stations are price takers, which means that electricity prices are input values that don't change along the solution process. Considering hydro stations as price takers is not realistic because the generation and pumping orders alter the electricity prices and originate a reduction of the profit. Therefore, the described approach can be useful for generation agents owning a large share of hydro stations or for countries in which hydro generation is significant. Finally, the results obtained for Test 4 considering an hydro connection is, proves that pumping together with the installation of hydro stations in the same river provides an increase of the operation profit.

\section{ACKNOWLEDGMENT}

The first author is grateful to EDP Gestão da Produção, namely to Eng. Virgílio Mendes and Eng. José Sousa for providing guidance during the preparation of his MSc Thesis.

\section{REFERENCES}

[1] J. C. Sousa, V. T. Mendes, J. T. Saraiva, "Estimation of the Remuneration of Hydro Plants in a Market Environment Using an Iterative Under-Relaxation Approach", in Proc. of the 2009 IEEE Bucharest Power Tech, Bucharest, Romenia, 28 June - 2 July 2009.

[2] G. S. Sampaio, J. T. Saraiva, J. C. Sousa, V. T. Mendes, "Optimization of the Operation of Hydro Stations in Market Environment Using Genetic Algorithms", in Proc. of the European Electricity Market Conference, EEM'13, Stockholm, May 2013.

[3] H. Pousinho, V. Mendes, J. P. Catalão, "Profit-Based Head-Dependent Short-Term Hydro Scheduling Considering Risk Constraints", in Proc. 2011 IEEE Trondheim Power Tech, Trondheim, pp. 1 - 6, June 2011.

[4] O. B. Fosso, M. M. Belnes, "Short-Term Hydro Scheduling in a Liberalized Power System", in Proc. of the International Conf. on Power System Technology, vol. 2, pp. 1321 - 1326, November 2004.

[5] S.-C. Chang, et al., "Hydroelectric Generation Scheduling With An Effective Differential Dynamic Programming Algorithm", IEEE Transactions on Power Systems, vol. 5, no. 3, pp. 737-743, August 1990.

[6] A. Cohen, V. R. Sherkat, "Optimization-Based Methods for Operations Scheduling", in Proc. of the IEEE, vol. 75, no. 12, pp. 1574-1591, 1987.

[7] L. Martinez, S. Soares, "Primal and Dual Stochastic Dynamic Programming in Long Term Hydrothermal Scheduling", in Proc. IEEE/PES Transmission and Distribution Conference: Asia and Pacific, vol. 3, pp. 1283-1288, October 2004.

[8] Z. K. Shawwash, T. K. Siu, S. O. D. Russell, "The B. C. Short Term Hydro Scheduling Optimization Model", IEEE Transactions Power Systems, vol. 15, no. 3, pp. 1125 - 1131, August 2000.

[9] J. Garcia-Gonzalez, G. Castro, "Short-Term Hydro Scheduling with Cascaded and Head-Dependent Reservoirs Based on Mixed Integer Linear Programming", in Proc. of 2001 IEEE Porto Power Tech, Porto, September 2001.

[10]R. Naresh, J. Sharma, "Hydro System Scheduling Using ANN Approach", IEEE Transactions Power Systems, vol. 15, no. 1, pp. 388 395, February 2000.

[11]K. P. Wong, Y. W. Yong, "A Parallel Simulated Annealing Algorithm for Short-Term Hydro Scheduling", in Proc. of the Second Int. Forum on Applications of ANN to Power Systems, pp. 335-340, Yokohama, 1993.

[12] A. H. Mantawy, S. A. Soliman, M. E. El-Hawary, "A New Tabu Search Algorithm for the Long-Term Hydro Scheduling Problem", in Proc. Large Eng. Conf. Power Engineering, LESCOPE'2002, June 2002.

[13]P. T. Leite, A. F. M. Carneiro, A. L. F. Carvalho, "Energetic Operation Planning Using Genetic Algorithms", IEEE Transactions on Power Systems, vol. 17, no. 1, pp. 173 - 179, February 2002.

[14]C. Samudi, G. P. Das, P. C. Ojha, T. S. Sreeni, S. Cherian, "Hydrothermal Scheduling Using Particle Swarm Optimization", in Proc. IEEE 2008 T\&D Conference and Exposition, Chicago, April 2008.

[15]J. García-González, et al., "Under-relaxed Iterative Procedure for Feasible Short-Term Scheduling of a Hydro Chain", in Proc of 2003. IEEE Bologna Power Tech, Bologna, Italy, vol. 2, June 2003. 